\title{
Fear-of-intimacy-mediated zinc transport controls fat body cell dissociation through modulating Mmp activity in Drosophila
}

\author{
Tian $\mathrm{Wei}^{1,2}$, Xiaowen $\mathrm{Ji}^{1,2}$, Qunhui $\mathrm{Yu}^{1,2}$, Guangying $\mathrm{Li}^{1}$, Lei $\mathrm{Wu}^{1}$, Yan Gao ${ }^{1}$ and Guiran Xiao $\mathbb{D}^{1 凶}$ \\ (c) The Author(s) 2021
}

Matrix metalloproteinases (Mmps) are pivotal extracellular proteinases that have been implicated in tumour invasion and metastasis. Drosophila fat body is important for energy storage and utilization, as well as biosynthetic and metabolic activities. The fat body undergoes remodelling during metamorphosis which is characterized by the dissociation of the fat body into individual cells. Mmps play important roles in the regulation of fat body cell dissociation. Here we show that a zinc transporter fear-of-intimacy (foi) is necessary for the cell dissociation of fat body in Drosophila. The progression of fat body cell dissociation was delayed by fat body-specific foi knockdown while it was accelerated by foi overexpression (OE). In essence, these phenotypes are closely associated with intracellular zinc homeostasis, which can be modulated by dietary zinc intervention or genetic modulation of other zinc transporters. Further study indicated that Mmp1 and Mmp2 levels could be transcriptionally regulated by zinc in vivo. Consistently, the retarded fat body cell dissociation caused by Mmp1 or Mmp2 RNAi could be regulated by modulating the expression of foi. Further, by using Drosophila models of malignant tumour Raf ${ }^{\mathrm{GOF}}$ scrib $^{-1-}$ and Ras $^{\mathrm{V} 12} \mathrm{Igl}^{-1-}$, we showed that the tumour growth, invasion and migration could be markedly inhibited by foi knockdown. These findings demonstrate a close connection between zinc levels and cell dissociation in vivo, and also suggest that manipulation of zinc levels may provide a novel therapeutic strategy for cancer.

Cell Death and Disease (2021)12:874; https://doi.org/10.1038/s41419-021-04147-z

\section{INTRODUCTION}

Mammalian matrix metalloproteinases (Mmps) participated in the degradation of various proteins in the extracellular matrix (ECM) [1]. Mmps have been implicated in the migration of normal and malignant cells through the basement membrane (BM), a specialized form of ECM that subtends all epithelial cells [2]. Emerging evidence indicated aberrant $\mathrm{Mmp}$ expression has been associated with multiple stages of cancer progression including tumour invasion and metastasis [3]. However, most clinical trials of Mmp inhibitors have failed, so alternative drug candidates and therapeutic targets are urgently required $[4,5]$.

Drosophila melanogaster has gained appreciation as a useful model for studying genetics, developmental biology and human diseases [1, 6]. Drosophila fat body is a tissue that is analogous to vertebrate liver and adipose tissue, involving many important roles in metabolic activities [7-9]. Drosophila fat body undergoes remodelling during early stages of metamorphosis, and the fat body is gradually remodelled from a single-cell layer of attached polygonal cells into free floating as single cells or as small clusters [10]. Generally, the integrity of tissue or organ is maintained with $\mathrm{BM}$ in animals [11]. The destruction of cell-cell and cell-BM adhesion in fat body is a crucial step for the progression of cell dissociation [12]. There are two Mmps (Mmp1 and Mmp2) in Drosophila [13-15]. Previous work showed that Mmp1 and Mmp2 are required for fat body cell dissociation in Drosophila [16]. Mmp1 cleaves cell-cell junctions mediated by DE-cadherin, while Mmp2 degrades BM components maintained by integrin BPs [16]. The remodelling of fat body which involves Mmps is widely found in insects during metamorphosis, but the regulation of this process remains largely unknown.

Zinc is an essential trace element for all organisms $[17,18]$. The SLC39 (Zrt/IRT-like proteins, ZIPs) family members regulate zinc influx from the extracellular medium or vesicular organelles into the cytoplasm, whereas the SLC30 (Zn-transporters, ZnTs) family members transport zinc in opposite orientations [19, 20]. Mmps could be activated by the expression of zinc transporters including ZIP5, ZIP6, ZIP7, ZIP8 and ZIP10 [21]. However, the regulatory mechanism of zinc on Mmps in vivo still remains unclear.

There are at least ten putative ZIP family members in Drosophila $[19,20,22,23]$. Among them, fear-of-intimacy (foi)/CG6817 shares the highest overall homology with human ZIP6 and ZIP10 $[20,24,25]$. In both yeast and mammalian cell assays in vitro, foi was dissected as a zinc transporter localized to the cell plasma membrane $[20,25]$. Foi has been found to be involved in several important physiological processes, such as gonad and trachea morphogenesis, myogenesis and glial cell migration in Drosophila $[24,26,27]$.

In this study, we demonstrated that foi maintains zinc homeostasis in the fat body of Drosophila. Alteration in the expression of foi in the fat body, or modulation of dietary zinc availability,

\footnotetext{
${ }^{1}$ School of Food and Biological Engineering, Hefei University of Technology, Hefei, Anhui, China. ${ }^{2}$ These authors contributed equally: Tian Wei, Xiaowen Ji, Qunhui Yu. 凶email: xiaoguiran@hfut.edu.cn

Edited by Dr Kim McCall
}

Received: 9 January 2021 Revised: 17 August 2021 Accepted: 8 September 2021

Published online: 25 September 2021 
significantly modified the progression of fat body cell dissociation. Further study indicated that the altered transcription of Mmps is responsible for the modulation of zinc on fat body cell dissociation. In addition, using the Drosophila malignant tumour models, Raf ${ }^{\mathrm{GOF}} \mathrm{scrib}^{-1-}$ and $\mathrm{Ras}^{\mathrm{V} 12} \mathrm{Igl}^{-/-}$, we found that the tumour growth, invasion and migration could be remarkably restrained by foi RNAi.

\section{MATERIALS AND METHODS \\ Drosophila strains and culture media}

Unless otherwise noted, flies were normally reared on standard cornmeal media at $25^{\circ} \mathrm{C}$. The following stocks were used: (1) w1118 (V\#60000), (2) UAS-foi RNAi (V\#10102), (3) UAS-Mmp1 RNAi (V\#101505), (4) UAS-Mmp2 RNAi (V\#107888) were obtained from the Vienna Drosophila RNAi Center. (5) Lsp2-Gal4 (B\#6357) and (6) Cg-Gal4 (B\#7011) were obtained from the Bloomington Drosophila Stock Center. (7) UAS-foi OE [24] was a kind gift from Dr. Mark Van Doren. (8) UAS-dZnT1 OE [28] was a kind gift from Dr. Bing Zhou. (9) Viking-GFP, (10) y,w,ey-flp; tub-Gal80 FRT40A; Act- ${ }^{+}-G a l 4$ UAS-GFP, (11) w;lg| ${ }^{4}$ FRT4OA UAS-Ras ${ }^{\text {V12 } / C y o ; S b / T M 6 B, ~(12) ~ y, w, e y-f l p ; ~ A c t-~}$ $\mathrm{y}^{+}$-Gal4 UAS-GFP; FRT82B tub-Gal80 and (13) w; Adv/Cyo; UAS-Raf ${ }^{\text {GOF }}$ FRT82B scrib ${ }^{1} / T M 6 B$ were generously provided by Dr. Jose C. PASTORPAREJA.

The concentrations of supplemented metals or metal chelators used were as follows: $25 \mu \mathrm{M} \mathrm{N}, \mathrm{N}, \mathrm{N}^{\prime}, \mathrm{N}^{\prime}$-tetrakis (2-pyridylmethyl) ethylenediamine (TPEN) (Sigma, Cat\#P4413), 2 mM ZnCl 2 (Sigma, Cat\#746355) and $2 \mu \mathrm{M}$ Zinpyr-1 (Santa Cruz Biotechnology, sc-213182).

\section{Eclosion rate assay}

$\mathrm{Cg}$-Gal4 homozygous flies were crossed to transgenic flies. After 3 days mating, the parents were transferred to juice-agar plates to lay eggs for $24 \mathrm{~h}$. Newly hatched first-instar larvae were transferred to normal food. The density was controlled to 70 larvae/vial. The total number of emerging adults of each genotype was counted. Six parallel group tests were conducted for each genotype, and the experiments were repeated at least three times.

\section{Alkaline phosphatase (ALP) activity assay}

Samples (fat bodies of 15 larvae) were lysed in ALP lysis buffer (10 mM Tris$\mathrm{HCl}, 0.5 \mathrm{mM} \mathrm{MgCl} 2$ and $0.1 \%$ Triton X-100, $\mathrm{pH} 7.4)$, then $1 \sim 2 \mu \mathrm{g}$ total protein was incubated in $1.0 \mathrm{M}$ diethanolamine, $0.5 \mathrm{mM} \mathrm{MgCl}$ and $150 \mathrm{mM}$ p-nitrophenyl phosphate (pNPP). The absorbance at $405 \mathrm{~nm}$ was measured after incubation for $30 \mathrm{~min}$ at $25^{\circ} \mathrm{C}$.

\section{Quantitative measurements of fat body cell dissociation}

The fat body was dissected out from each animal at different developmental stages under Nikon camera. ImageJ software was employed to calculate the total area of fat-body tissues of each genotype and the area of its non-dissociated fat-body tissues (area non-dissociated). The degree of fat body cell dissociation was calculated using the following formula: Dissociation $(\%)=100 \% \times($ total area - non-dissociated area)/total area [16]. Dissociation (\%) was compared among different genotypes at the indicated developmental stage. For analysing fat body cell dissociation of each genotype at one developmental stage, 3-10 animals were used for each independent replication and three independent replications were carried out.

\section{Quantitative measurements of gap area in the fat body}

ImageJ software was employed to calculate the total area of fat-body tissues of each genotype and the area of gaps in fat-body tissues. The ratio of gap area in the fat bodies was calculated using the following formula: Gap area $(\%)=100 \% \times$ gap area/area total. Gap area (\%) was compared among different genotypes at $7 \mathrm{~h}$ after puparium formation (APF).

\section{RNA isolation, semiquantitative RT-PCR and quantitative real- time PCR}

Total RNA was extracted with Trizol reagent (Invitrogen, Carlsbad, CA, USA). cDNA was reversely transcribed from $2 \mu \mathrm{g}$ total RNA with TransScript Reverse Transcriptase (TransGen Biotech Co, Beijing, China). Semiquantitative RT-PCR was performed using gene-specific primers to amplify partial regions of the gene foi. RNA isolation and reverse transcription were performed independently for three times.
qPCR was carried out in a $20 \mu$ reaction volume containing $10 \mu \mathrm{l}$ of $2 \times$ TransStart Green qPCR SuperMix (TransGen Biotech Co., Beijing, China), $1 \mu \mathrm{l}$ of first-strand CDNA template (as prepared above) and $0.4 \mathrm{mM}$ of each primer. The Real-Time PCR Detection System (Roche, Switzerland) was used according to the manufacturer's instructions. The ribosomal protein 49 gene (rp49) was used as the control. RNA isolation and reverse transcription were performed independently for three times.

The primers used for RT-PCR and $\mathrm{QPCR}$ were:

foi-F: 5'-TGATTCATTTCCACGCAGTTC-3',

foi-R: 5'-ATCCATATTGCTACGACGACGAGA-3';

Mmp1-F: 5'-AGGACTCCAAGGTAGACACAC-3',

Mmp1-R: 5'-TTGCCGTTCTTGTAGGTGAACGC-3';

Mmp2-F: 5'-AACGACGACCGCATGAAGGTG-3',

Mmp2-R: 5'-GAAGTGGTTGATCCTTAGCTCCC-3';

rp49-F: 5'- GCACCAAGCACTTCATCC-3',

rp49-R: 5'-CGATCTCGCCGCAGTAAA-3'.

\section{Immunohistochemistry}

The third-instar larvae were dissected in cold PBS, the dissected tissues were fixed in $4 \%$ formaldehyde in PBS for $10 \mathrm{~min}$ at room temperature, stained and mounted following standard procedures [29]. The following antibodies and dyes were used: rat anti-DE-cadherin (DCAD2, 1:100 Developmental Studies Hybridoma Bank, DSHB, USA), mouse anti-Mmp1 (1:100 DSHB) and mouse anti-integrin $\beta$ PS (CF. 6G11, 1:100, DSHB). The antibody of Mmp2 was gifted from Dr. Sheng Li [16]. The fluoresceinconjugated secondary antibodies used were FITC-conjugated goat antimouse lgG (1:500 for Mmp1, 1:500 for integrin $\beta P S)$, goat anti-rabbit lgG (1:500 for Mmp2) and Cy3-conjugated goat anti-rat IgG (1:500 for DEcadherin). For DAPI staining, samples were incubated in $50 \mathrm{ng} / \mathrm{ml}$ DAPI for $12 \mathrm{~min}$. Slices were mounted with $50 \%$ glycerol/PBS. Confocal images were taken with a Zeiss LSM710 Meta confocal microscope.

For Zinpyr-1 staining, the dissected tissues were fixed in $4 \%$ formaldehyde in PBS for $10 \mathrm{~min}$ at room temperature, $2 \mu \mathrm{M}$ Zinpyr-1 stained for $60 \mathrm{~min}$ at room temperature, washed thrice with PBS and mounted with $50 \%$ glycerol/PBS. The fluorescence signal was examined by Nikon Ti2 fluorescence microscope.

\section{Assessment of total Mmp enzyme activity by gelatin zymography}

Gelatin zymography was employed to determine the total Mmp enzyme activity of fat body samples. Unless otherwise noted, proteins were made from 50 fat bodies. Briefly, the dissected fat bodies were washed with cold PBS for three times, and extracted with PBST containing protease inhibitors. Protein concentrations were measured by the BCA Protein Assay Kit (Cat\#23227, Thermo Scientific). Proteins were loaded onto the gel with equal amounts of protein per lane. Samples were run on SDS-PAGE (10\% gel containing $0.1 \%$ gelatin; Cat 10010328 , Sinopharm Chemical Reagent Co., Ltd.). After electrophoresis, gels were incubated with Renaturing Buffer (prepare $200 \mathrm{ml}$ of $2.5 \% \mathrm{v} / \mathrm{v}$ Triton X-100 in $\mathrm{dH}_{2} \mathrm{O}$ ), then stained with Coomassie blue (prepare 1 I of $0.5 \%$ Coomassie blue R-250, $5 \%$ methanol and $10 \%$ acetic acid in $\mathrm{dH}_{2} \mathrm{O}$ ) [30]. All the experiments were repeated at least three times. ImageJ software was employed to quantify the Mmp activity by calculating the hydrolysis area in the lane. All data were normalized to the level in controls.

\section{Fluorescence microscopy}

The whole bodies of tumour larvae were observed with a Nikon ECLIPES Ti2-U microscope (Nikon, Tokyo, Japan) at 12 days after egg laying (AEL). The morphology analysis was performed as described previously [31]. More than ten tumour larvae were recorded per genotype, and each experiment was repeated at least three times.

To further investigate tumour growth, the cephalic complexes, including eye imaginal discs, brain lobes and ventral nerve cord (VNC), were dissected in cold PBS within 20 min, fixed in $4 \%$ paraformaldehyde for 10 min, washed once with PBS and imaged immediately at 12 days AEL. ImageJ was employed to quantify the size and fluorescence intensity of tumours [31].

\section{Statistical analysis}

Data were analysed by Student's $t$ test between groups, and one-way analysis of variance (ANOVA) was used for multiple groups. Statistical results were presented as mean $\pm \mathrm{SEM}$. Asterisks indicate critical levels of significance $\left({ }^{*} P<0.05,{ }^{* *} P<0.01\right.$ and $\left.{ }^{* * *} P<0.001\right)$. 


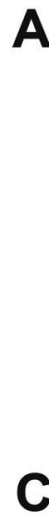

A
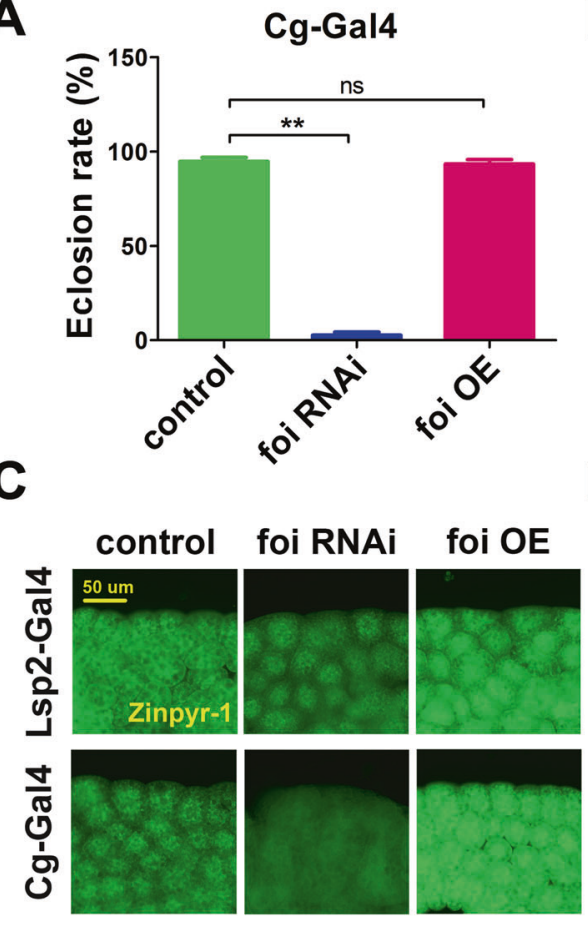

B

$\frac{\text { Cg-Gal4 > foi RNAi }}{\mathrm{NF} \quad 2 \mathrm{mM} \mathrm{ZnCl}{ }_{2} \quad 25 \mu \mathrm{M} \text { TPEN }}$
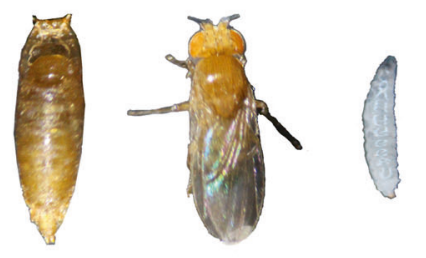

$\mathbf{D}$

Lsp2-Gal4

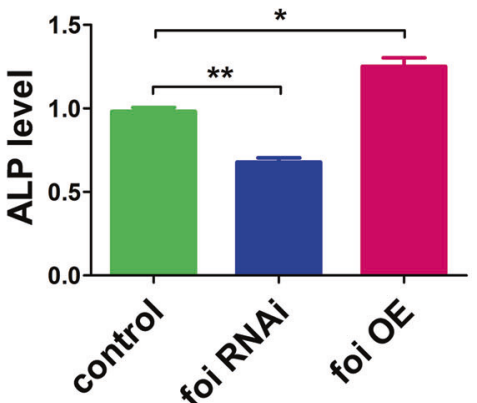

Fig. 1 Foi maintains zinc homeostasis in the fat body and modulates the development of Drosophila melanogaster. A Fat body-specific foi knockdown ( $\mathrm{Cg}$-Gal4 $>$ foi RNAi) resulted in dramatically reduced eclosion rate in Drosophila. $n=70$ larvae per vial, $n=6$ vials per group. B The defects of RNA-interference foi $\left(\mathrm{Cg}-\mathrm{Gal} 4>\right.$ foi $\mathrm{RNAi}$ ) flies could be absolutely rescued by dietary zinc supplementation $\left(2 \mathrm{mM} \mathrm{ZnCl}_{2}\right)$ while aggravated by zinc chelator ( $25 \mathrm{mM}$ TPEN). C The Zinpyr-1 staining revealed that fat body-specific foi OE resulted in zinc accumulation while foi RNAi decreased zinc particles in the fat body cells. D The activity of ALP was significantly reduced in $L s p 2-G a l 4>$ foi RNAi larvae while increased in Lsp2-Gal4 > foi OE larvae. w1118 flies driven by Cg-Gal4 or Lsp2-Gal4 serve as a blank control. All the experiments were conducted independently at least for 3 times. ns: not significant, ${ }^{*} P<0.05,{ }^{* *} P<0.01,{ }^{* * *} P<0.001$, two-tailed Student's $t$ test.

\section{RESULTS}

Fat body modulation of foi affects the zinc homeostasis and the development of Drosophila melanogaster

$\mathrm{Cg}$-Gal4 is a driver specifically expressing the activator Gal4 in the fat body and haemocytes of flies [32,33]. When foi was knocked down with $\mathrm{Cg}$-Gal4, Drosophila displayed developmental arrest at the pupal stage (died prior to eclosion) (Fig. 1A). To distinguish the defects of $\mathrm{Cg}$-Gal4 > foi RNAi in the fat body or the haemocytes, foi was specifically knocked down in the haemocytes using a haemocyte-specific driver $\mathrm{He}$-Gal4 [33], no obvious defect was observed (data not shown). These data suggested that foi RNAi in the fat body resulted in developmental defects in Drosophila.

Interestingly, the eclosion rate of $\mathrm{Cg}$-Gal4 $>$ foi $R N A i$ was completely rescued by zinc supplementation in food from $3 \%$ to $100 \%$ (Fig. 1A, B), while all flies died at the second-instar larval stage when raised on zinc-deficient food (Fig. 1B). These data suggest that the expression of foi in fat body is important for development and the function of foi is closely related to zinc.

The role of foi in the fat body of Drosophila has not been investigated before. It has been reported that Zinpyr-1 is a zinc sensor that particularly amenable to intracellular work, in response to intracellular $\mathrm{Zn}^{2+}[34,35]$. As shown in Fig. 1C, zinc accumulation was observed in foi $\mathrm{OE}$, while the zinc signal was attenuated in foi RNAi. Cg-Gal4 is strongly expressed at all the stages of development [32]. In order to identify the function of foi in the fat body, foi RNAi was driven by the other fat body driver Lsp2-Gal4, which initiates expression in the fat body cells at the mid-instar transition midway through the third larval instar [36-38]. When the expression of foi was modulated by Lsp2Gal4, the Zinpyr-1 staining results are consistent with $\mathrm{Cg}$-Gal4 (Fig. 1C). ALP activity is considered as a sensitive indicator of intracellular zinc level [39-41]. As shown in Fig. 1D, foi knockdown in the fat body led to a reduction of ALP activity, whereas foi OE resulted in elevated activity. Taken together, foi modulates zinc homeostasis in the fat body of Drosophila.

\section{The zinc homeostasis mediated by foi is required for fat body cell dissociation}

It is known that the fat body remodelling is an essential developmental event which persists throughout pupal development [42]. We next investigated the influence of foi on the dissociation of the fat body into individual fat cells: they gradually become spherical and then physically detach from each other during the early pupal stage [16].

In order to directly observe the morphological changes, we dissected the fat body of flies from the white prepupal stage (WPP) to $10 \mathrm{~h}$ APF and calculated the ratio of fat body cell dissociation. The fat bodies of flies were dissected out to monitor cell dissociation at 8,9 and $10 \mathrm{~h}$ APF. As shown in Fig. 2A, under our experimental conditions, the fat body cells of wild-type flies intimately adhere to each other and form a single-cell layer of tissues until $8 \mathrm{~h}$ APF and appear with obvious cell dissociation at 10 APF. According to the results, the rate of cell dissociation was significantly reduced in foi $R N A i(\sim 23 \%)$ while being dramatically increased in foi OE $(\sim 57 \%)$, compared to control $(\sim 39 \%)$ at $10 \mathrm{~h}$ APF (Fig. 2B). These results reveal that foi manipulates the progression of the fat body cell dissociation.

Then we tested whether dietary zinc intervention could affect the modulation of foi on cell dissociation. The results showed that zinc supplement rescued the retarded cell dissociation caused by foi RNAi and enhanced the precocious dissociation caused by foi OE (Fig. 2C), showing a $9 \%$ and $13 \%$ increase in dissociation rate, respectively (Fig. 2D). By contrast, zinc depletion in food significantly inhibited cell dissociation of fat body at $10 \mathrm{~h} \mathrm{APF}$ 


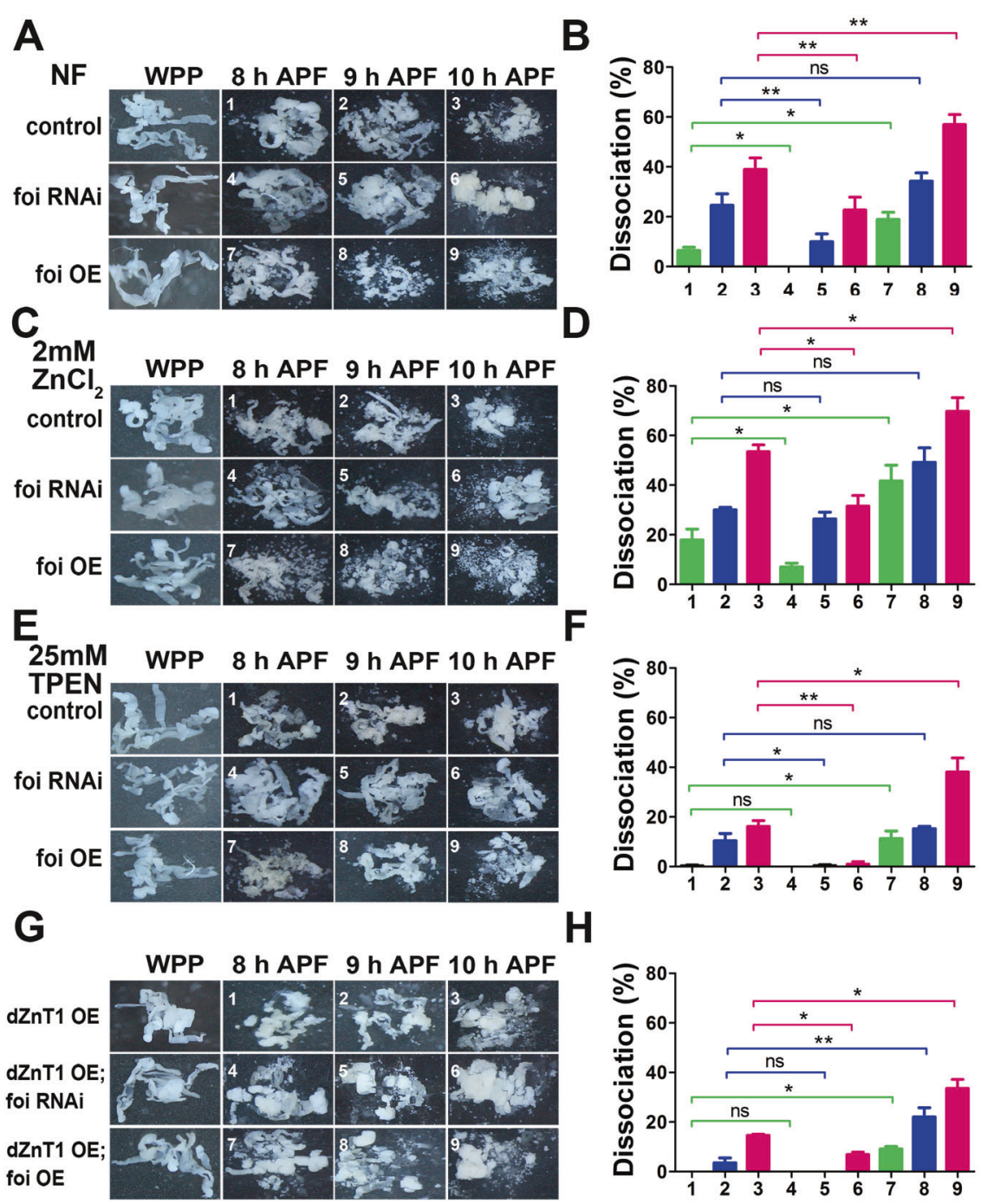

Fig. 2 Cytosolic zinc affects the progression of the fat body cell dissociation. A, B The fat body cell dissociation was greatly delayed in $L s p 2-$ Gal4 > foi RNAi while accelerated in Lsp2-Gal4 > foi OE. C, D Dietary zinc supplementation was able to rescue the retarded fat body cell dissociation induced by fat body-specific foi RNAi, while enhance the precocious the progression induced by foi OE. E, F Zinc chelator TPEN had the capability of rescuing the precocious fat body cell dissociation induced by foi OE, while aggravating the retarded fat body cell dissociation induced by foi RNAi. G, H ZnT1 OE in the fat body dramatically rescued the precocious cell dissociation caused by fat body-specific foi $\mathrm{OE}$, while enhanced the retarded cell dissociation induced by foi RNAi. All the experiments were conducted independently at least for 3 times. ns: not significant, ${ }^{*} P<0.05,{ }^{* *} P<0.01,{ }^{* * *} P<0.001$, two-tailed Student's $t$ test.

(Fig. 2E), with $22 \%$ and $19 \%$ decrease in foi RNAi and foi OE animals, respectively (Fig. 2F). In addition, compared with normal diet, zinc supplementation induced the fat body cell dissociation (from $39 \%$ to $54 \%$ ), while zinc deficiency reduced this progression (from $39 \%$ to $18 \%$ ) in wild-type animals at $10 \mathrm{~h}$ APF (Fig. 2A-F). This indicates that the regulation of foi on the progression of the fat body cell dissociation could be modulated by dietary intervention of zinc and further strengthens the notion that zinc is involved in the fat body cell dissociation.

As an alternative to examine the role of zinc homeostasis in the progression of the fat body cell dissociation, a well-established plasma membrane zinc transporter dZnT1/CG17723 (also named ZnT63C) [41] was selected to test the effect on fat body cell dissociation. dZnT1 functions in the opposite direction with foi $[20,28]$. We observed that fat body-specific $d Z n T 1$ OE vastly postponed the fat body cell dissociation (from 39\% to 15\%) and its dissociation rate was even lower than that of foi RNAi $(\sim 23 \%)$ at $10 \mathrm{~h}$ APF. Besides, the retarded fat body cell dissociation of foi RNAi could be aggravated by $d Z n T 1$ OE (from $23 \%$ to $7 \%$ at $10 \mathrm{~h} \mathrm{APF);} d Z n T 1 \mathrm{OE}$ was able to rescue the premature cell dissociation caused by foi $\mathrm{OE}$ (from $15 \%$ to $34 \%$ at $10 \mathrm{~h}$ APF) (Fig. $2 \mathrm{G}, \mathrm{H}$ ). This suggests that cytoplasmic zinc promotes the fat body cell dissociation.

Taken together, our results reveal that foi acts a pivotal part in the fat body cell dissociation; moreover, the function of foi on fat body cell dissociation is powerfully associated with cytoplasmic zinc levels.

Foi is required for the structural stabilization of fat body cells Tissue remodelling has been reported to be involved in normal development, pathological wound healing, cancer invasion and metastasis [11, 16, 43]. Cell-cell and cell-BM junctions are disrupted during Drosophila fat body remodelling [16]. To reveal the cell shape, the phalloidin staining of F-actin, a key component of the cytoskeleton was determined here (Fig. 3A). The two important adhesion proteins DE-cadherin and integrin $\beta P s$ were employed to monitor cell-cell and cell-BM junctions, respectively (Fig. 3B, C). With the help of these hallmarks, the critical time of fat body remodelling could be detected. We carefully dissected the fat body of foi OE animals at 8 APF and found that their fat bodies are easily disintegrated during immunostaining; therefore, we 


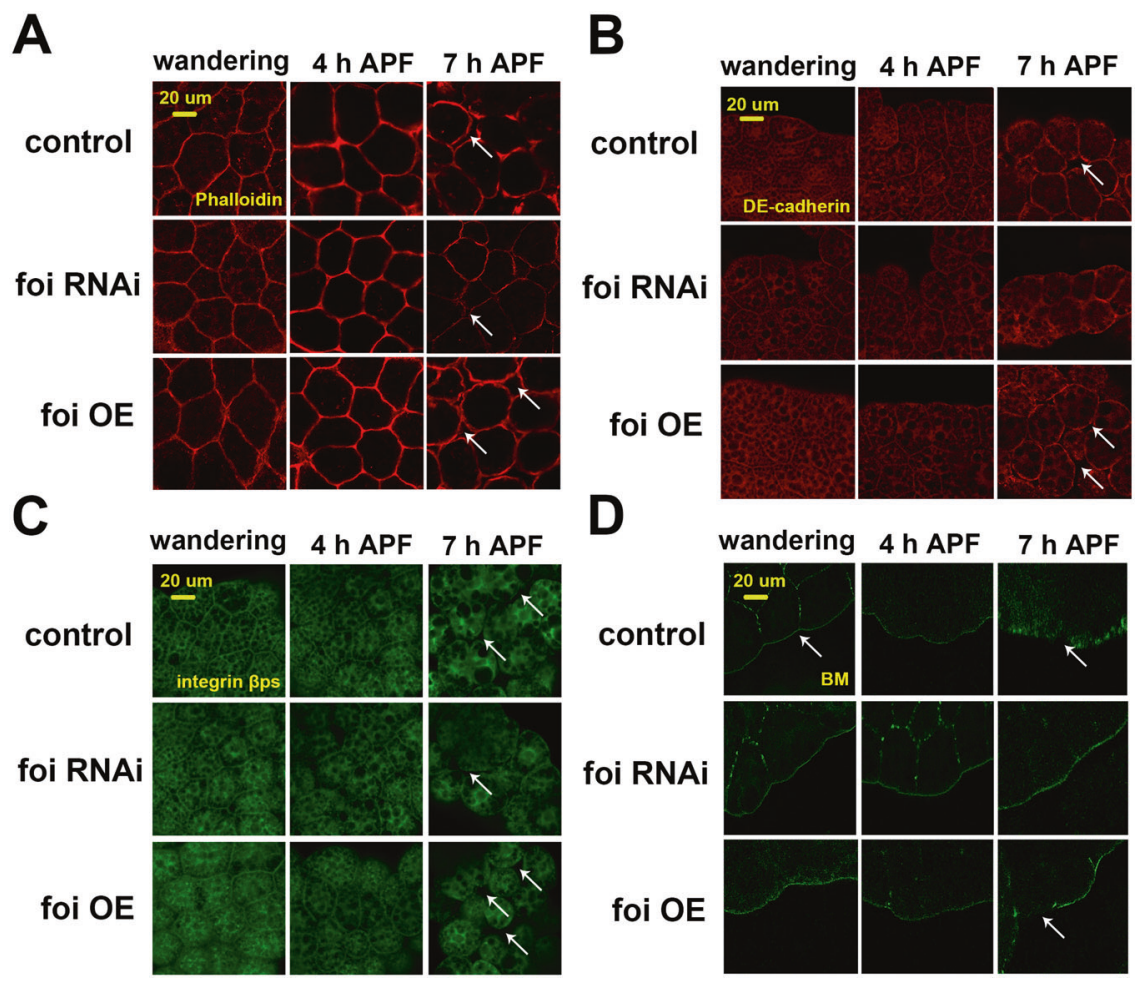

Fig. 3 Foi is required for the structural stabilization of fat body cells. The fat body structure was investigated with four hallmarks at the wandering stage, $4 \mathrm{~h}$ APF and $7 \mathrm{~h}$ APF. A Phalloidin staining revealed the shape of the fat body cells. B, C Immunostaining of DE-cadherin (B) and integrin $\beta \operatorname{Ps}(\mathbf{C})$ were used to monitor the cell-cell junctions and cell-basement membrane (BM) junctions, respectively. D Viking-GFP revealed the integrity of the BM. A nearly intact BM was observed in the fat body of $L s p 2-G a l 4>$ foi RNAi animals, while the BM was broken in Lsp2-Gal4 > foi OE animals. w1118 flies driven by Lsp2-Gal4 serve as a blank control. The arrows in (A-C) indicated the gaps between cells, and the arrows in (D) showed the degraded BM.

examined the four hallmarks of developmental profiles in the remodelling fat body at wandering stage, $4 \mathrm{~h}$ and $7 \mathrm{~h}$ APF. Various staining methods indicated that intercellular gaps were present in foi $O E$ at $7 \mathrm{~h}$ APF, whereas cell-to-cell adhesion was relatively tight in foi RNAi (Fig. $3 \mathrm{~A}-\mathrm{C}$ ). We quantified the gap area of the fat body cell dissociation at $7 \mathrm{~h}$ APF and found that the gap area was strongly increased by $6 \%$ in foi $O E$ flies, while almost disappeared in foi RNAi flies, in comparison to wild-type flies (Fig. S1A). Interestingly, neither foi knockdown nor OE has any effect on the expression of both DE-cadherin and integrin BPs (Fig. S1B, C).

The intact BM is gradually destroyed until nearly disappeared at the late stage after puparium formation [16]. Viking-GFP is a functional GFP-trap fusion into the Collagen IV chain vkg, revealing the integrity of BM [16]. Robust GFP signal exhibited in foi RNAi files which indicated integrated BM, while the signal nearly disappeared in foi OE flies at $7 \mathrm{~h}$ APF (Fig. 3D). Furthermore, statistical analysis showed that fluorescence signal (Viking-GFP) was significantly reduced in wild-type larvae at $7 \mathrm{~h} \mathrm{APF}$, compared to the larvae at wandering stage or $4 \mathrm{~h}$ APF (Fig. S1D). The data were consistent with previous report that BM was gradually destroyed during development [16]. The signal in foi OE was weaker (reduced $\sim 32 \%$ ) than that in wild-type at $7 \mathrm{~h}$ APF. foi RNAi showed no significant difference in fluorescence signal at the three time points of development (Fig. S1D). Taken together, these results demonstrated that foi modulates the adhesion and structural stabilization between cells.

\section{Foi regulates the transcription of Mmps}

To further identify the mechanism underlying foi's effect on the progression of fat body cell dissociation, the activity of Mmps was examined (Fig. 4A, B). Gelatin zymography [30] indicated that the total Mmp enzyme activity of fat body was significantly reduced in foi RNAi larvae but increased in foi OE larvae (Fig. 4A, B).
Mmp activity is controlled by a complex array of mechanisms such as the level of gene expression, mRNA translation and protein modification [44]. Anti-Mmp1 and anti-Mmp2 could be used to detect the level of Mmp1 [16] and Mmp2 in vivo (Fig. S2). Immunostaining suggested that the expressions of Mmp1 and Mmp2 were decreased (14\% and 49\%, respectively) in foi RNAi while increased (32\% and $40 \%$, respectively) in foi OE (Fig. 4C-F). This result was also confirmed by western blot analysis (Fig. S3). What is more, the expression of Mmps could be elevated by zinc and inhibited by TPEN (Fig. 4C-F). Subsequently, q-PCR results indicated that the mRNA levels of Mmp1 and Mmp2 were significantly down-regulated in foi RNAi larvae (Fig. 4G, H). The Mmp1 mRNA level showed slight up-regulation but without statistical significance (Fig. 4G); a dramatically up-regulated $M m p 2$ mRNA level could be observed in foi OE larvae (Fig. 4H).

Accordingly, the gene expression profiles of foi and Mmps in the fat body of wild-type flies (w1118) were examined by RT-PCR analysis at different time points of development, including the wandering stage, WPP and $8 \mathrm{~h}$ APF (Fig. S4). We found that gene expressions of foi, Mmp1 and Mmp2 were gradually elevated during the development (Fig. S4A). Zinc levels were also elevated during the development (Fig. S4B). All the above data indicated that developmental changes of foi in the fat body result in elevated zinc levels in cells, which will induce the transcription of Mmp1 and Mmp2 during development. The induced expression and protein activities of $\mathrm{Mmp1}$ and $\mathrm{Mmp2}$ are responsible for the modulation of fat body cell dissociation.

\section{The fat body cell dissociation defects caused by Mmps} knockdown could be altered by foi level

Previous work has shown that the fat body cell dissociation was significantly delayed in Mmp1 RNAi and Mmp2 RNAi at the late stage of APF [16]. In order to further confirm the functional interaction 

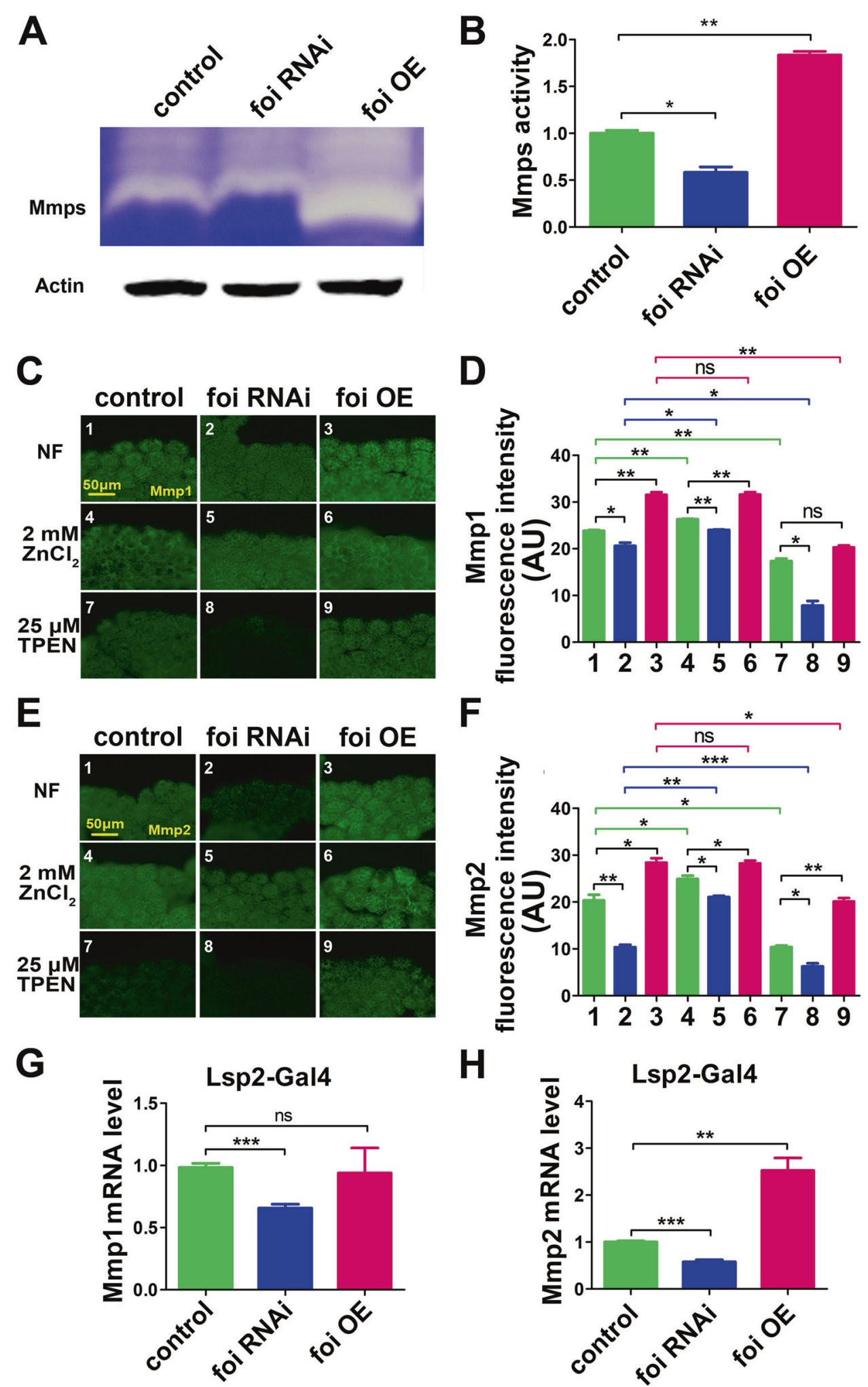

Fig. 4 Zinc affects the enzyme activity, protein and mRNA levels of the two Mmps. A Gelatin zymogram revealed that total Mmp enzyme activity was considerably diminished in $L s p 2-G a l 4>$ foi $R N A i$ larvae while increased in $L s p 2-G a l 4>$ foi OE larvae. B Quantitative measurement of (A). C-F Protein levels of both Mmp1 and Mmp2 in the fat body were reduced in Lsp2-Gal4 > foi RNAi larvae while increased in Lsp2-Gal4 > foi $O E$ larvae. Dietary zinc supplementation was able to elevate the expression of Mmps, whereas zinc chelator TPEN can reduce their expression. G, H Both Mmp1 and Mmp2 mRNA levels were significantly down-regulated in Lsp2-Gal4 > foi RNAi larvae, whereas a dramatically up-regulated Mmp2 mRNA level could be detected in $L s p 2-G a l 4>$ foi OE larvae. w1118 flies driven by $L s p 2-G a l 4$ serve as a blank control. All the experiments were conducted independently at least for 3 times. ns: not significant, ${ }^{*} P<0.05,{ }^{* *} P<0.01,{ }^{* * *} P<0.001$, two-tailed Student's $t$ test. 
A

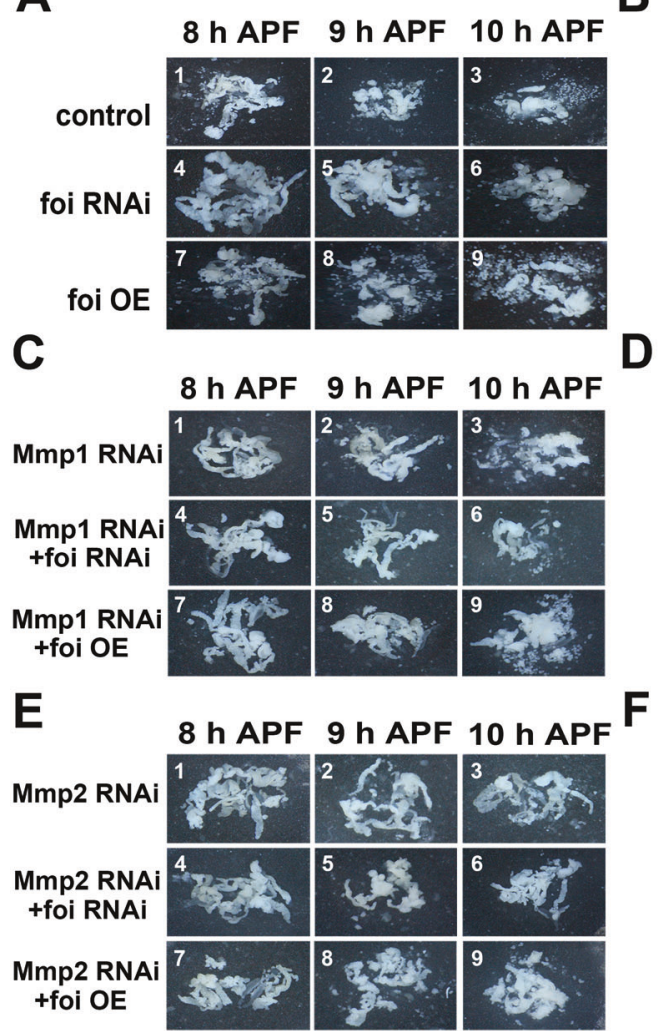

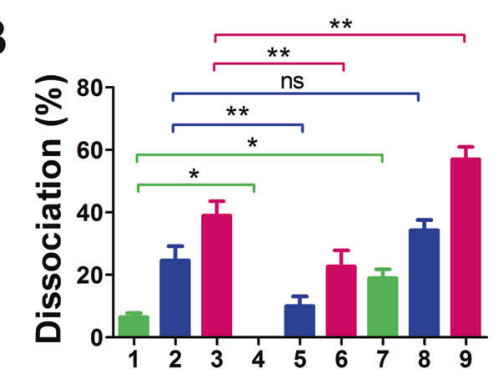

D
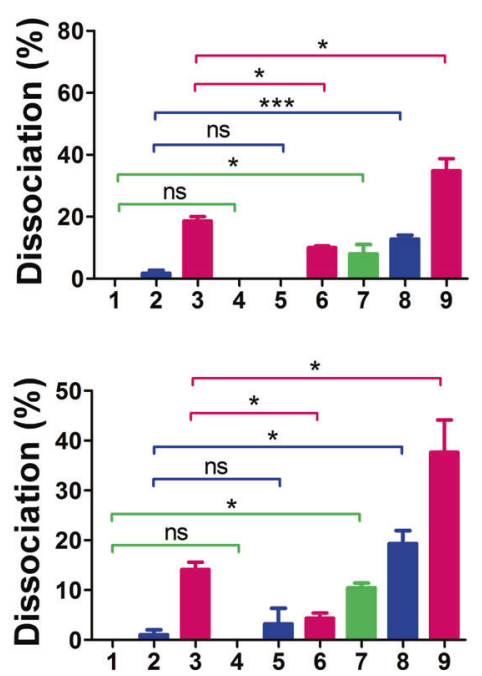

Fig. 5 Retarded fat body cell dissociation caused by Mmps knockdown could be rescued by foi OE. A, B Fat body cell dissociation was significantly delayed in $L s p 2-G a l 4>$ foi RNAi, whereas a significant advance in fat body cell dissociation was also observed in $L s p 2-G a l 4>$ foi $O E$. C, D The retarded fat body cell dissociation caused by Mmp1 RNAi could be enhanced by foi RNAi while rescued by foi OE. E, F foi RNAi

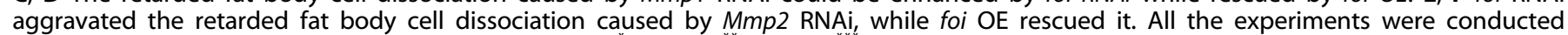
independently at least for 3 times. ns: not significant, ${ }^{*} P<0.05,{ }^{* *} P<0.01,{ }^{* * * *} P<0.001$, two-tailed Student's $t$ test.

between Mmps and foi, we used a combination of genetic approaches to investigate the effects of foi on the defects of Mmps' RNAi in Drosophila. As revealed by Fig. 5A-F, the retarded cell dissociation in the fat body of Mmp1 RNAi and Mmp2 RNAi was aggravated by foi RNAi (dissociation rate was from $19 \%$ to $10 \%$ and from $14 \%$ to $4 \%$, respectively), and rescued by foi $\mathrm{OE}$ (dissociation rate was raised to $35 \%$ and $38 \%$, respectively). All these data suggested that modulating zinc homeostasis in cytoplasm by altering the expression of foi could affect the defects of Mmps knockdown.

\section{The mechanism of foi regulates cell dissociation would be applied in modulating tumour invasion}

In Drosophila eye-antennal discs, cooperation between the classical oncoprotein Ras ${ }^{\mathrm{V} 12}$ or Raf ${ }^{\mathrm{GOF}}$ and tumour suppressor lethal giant larvae (lgl) or scribbled (scrib) mutation gives rise to metastatic tumour model that exhibits many phenotypic characteristics observed in human cancers $[45,46]$. It is reported that the massive Mmp1 activation is essential for BM degradation and epithelial to mesenchymal transition (EMT) progression in malignant Raf ${ }^{\mathrm{GOF}-}$ $\mathrm{scrib}^{-1-}$ flies $[47,48]$. We hence wondered whether the cellular zinc could regulate tumour growth and invasion in vivo. Tumour cells overgrew in the eye-antennal discs of the malignant model $\mathrm{Raf}^{\mathrm{GOF}} \mathrm{scrib}^{-1-}$ flies and metastasized into several places (Fig. 6A). Amazingly, silencing foi in tumour clones led to a significant reduction in tumour growth and metastasis (Fig. 6B). As a confirmation, eye defect caused by another weaker tumour model Ras $^{\mathrm{V} 12} \mathrm{lgl}^{-1-}$ was strongly rescued by foi knockdown (Fig. 6C). As shown in Fig. 6D, the tumour cells displayed overgrowth in the cephalic complex of Raf $^{G O F}{ }^{\text {scrib }^{-1-}}$ flies and invaded into the VNC at 12 days AEL (Fig. 6E). Silencing foi in the tumour clones strongly alleviated the tumour growth (the tumour size and fluorescence intensity of cephalic complex reduced by $42 \%$ and $38 \%$, respectively, Figs. $6 \mathrm{~F}$ and S5A, B) and invasive behaviour (Fig. 6G). The activated Mmp1 expression in $\mathrm{Raf}^{\mathrm{GOF}}{ }^{\mathrm{Scrib}}{ }^{-1-}$ flies was significantly suppressed when foi was knocked down in the tumour cells (Fig. $6 D-G)$. A statistical analysis of these data found that Mmp1 level of cephalic complex or ventral nerve cord (VNC) was remarkably reduced in foi RNAi tumour flies, showing $52 \%$ and $40 \%$ decrease, respectively, compared to $\mathrm{Raf}^{\mathrm{GOF}} \mathrm{Scrib}^{-1-}$ flies (Fig. S5C, D). Accordingly, the ALP activity in tumours with or without foi RNAi was detected, the results showed that zinc level was attenuated by $39 \%$ in foi RNAi, compared with Raf ${ }^{\mathrm{GOF}} \mathrm{scrib}^{-/-}$larvae (Fig. S6). These results suggest that reducing cytosolic zinc by inhibition of foi expression in tumour tissues could prevent tumour growth and invasion by reducing Mmp1 levels in Drosophila.

\section{DISCUSSION}

Cell dissociation is a process involved in many biological processes $[24,26]$ and some pathological processes, including tumour invasion and metastasis [49]. However, there are many details about the physiological importance or the regulation of this process that need to be clarified. The specific and efficient regulation of cell dissociation is absent till now. The insect fat body undergoes a dramatic remodelling process during metamorphosis in holometabolous insects [50]. Here we indicated Drosophila zinc transporter foi is necessary for the cell dissociation of fat body. Altered transcription of Mmp1 and Mmp2 in foi RNAi and foi $O E$ is responsible for the regulation of fat body cell dissociation. These molecular and morphology phenotypes of foi 

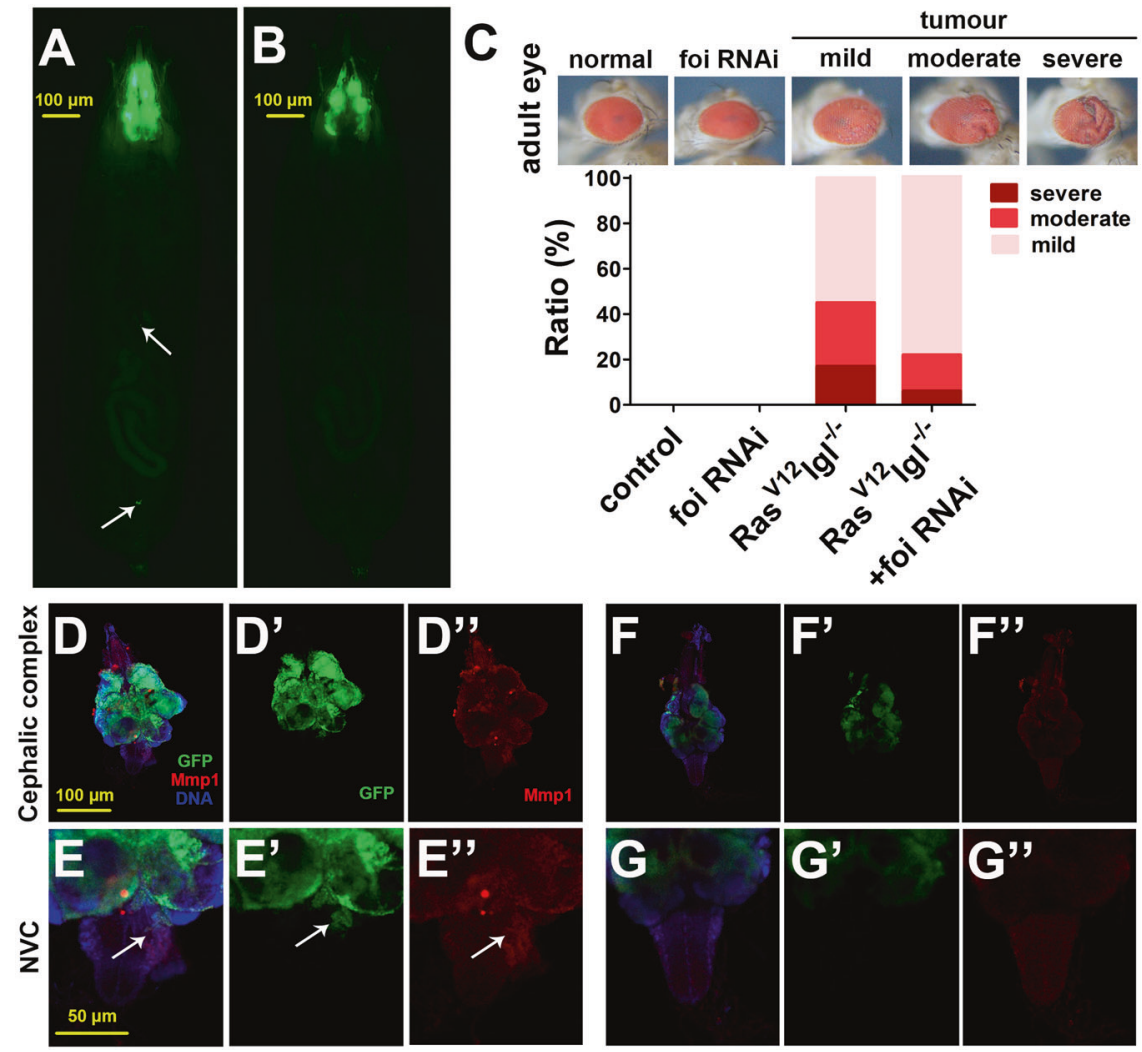

Fig. 6 Foi knocked down in tumour cells repressed tumour growth and invasion. A, B Tumour growth and metastasis was observed in Raf $^{\mathrm{GOF}}$ scrib $^{-1-}$ at 12 days AEL (A), which can be dramatically suppressed by foi RNAi (B). C Foi knockdown inhibited tumour phenotypes of $\mathrm{Ras}^{\mathrm{V} 12} \mathrm{gl}^{-1-}(n>200$ flies per group). When driven by eye-specific ey-Gal4, the foi RNAi did not cause any noticeable change in the morphology; 11118 flies driven by ey-Gal4 serve as a blank control. D, E Fluorescence micrographs of tumour cells and Mmp1 of eye-antennal disc and VNC were shown. Raf ${ }^{\mathrm{GOF}}$ scrib $^{-1-}$ flies displayed overgrowth in the cephalic complex (GFP signal), invasive behaviour and massive Mmp1 activation (red signal, white arrowheads). Nuclei were stained with DAPI. F, G Silencing foi in the tumour clones strongly reduced the tumour growth, invasive behaviour and Mmp1 activation.

$R N A i$ and foi $O E$ could be regulated by dietary zinc intervention. All the data strengthen the notion that zinc facilitates the cell dissociation of fat body in Drosophila by controlling $\mathrm{Mmp}$ expression. A model to explain the foi's effect on fat body cell dissociation is shown in Fig. 7.

Zinc is an essential trace element in cells where it participates in a variety of fundamental biological processes [20,51]. Mmps are expressed as inactive pro-enzymes, where the catalytic domain is shielded by a pro-domain that interacts with the zinc ion in the catalytic centre via a cysteine residue $[52,53]$. The Mmps have a common zinc-binding motif (HEXXHXXGXXH) in their active site, and their domains contain one catalytic zinc and one structural zinc [54]. The catalytic site becomes accessible to substrates through removal of the pro-peptide $[52,53]$. The endopeptidase activity is mediated by a zinc ion coordinated between three histidine residues that are present in the catalytic centre, and zinc ions directly participate in the bond-breaking step in the catalytic domain of Mmps $[52,53]$. In vitro evidence indicated that Mmp activity could be activated by zinc while suppressed by removal or chelation of zinc from its active site [55-57]. Besides, Yoo and his colleagues [58] reported that the Mmp9 activity in the brain of ZnT3-null male mice was increased because of the increased cytosolic free zinc levels.

Zinc is important for its role not only in enzyme catalysis but also in regulation on gene transcription [59]. It is reported that approximately $40 \%$ of putative zinc-binding proteins are transcription factors, which are essential for regulating gene expression $[60,61]$. These enable specific gene regulatory processes to be activated [60]. Here we showed that the mRNA and protein

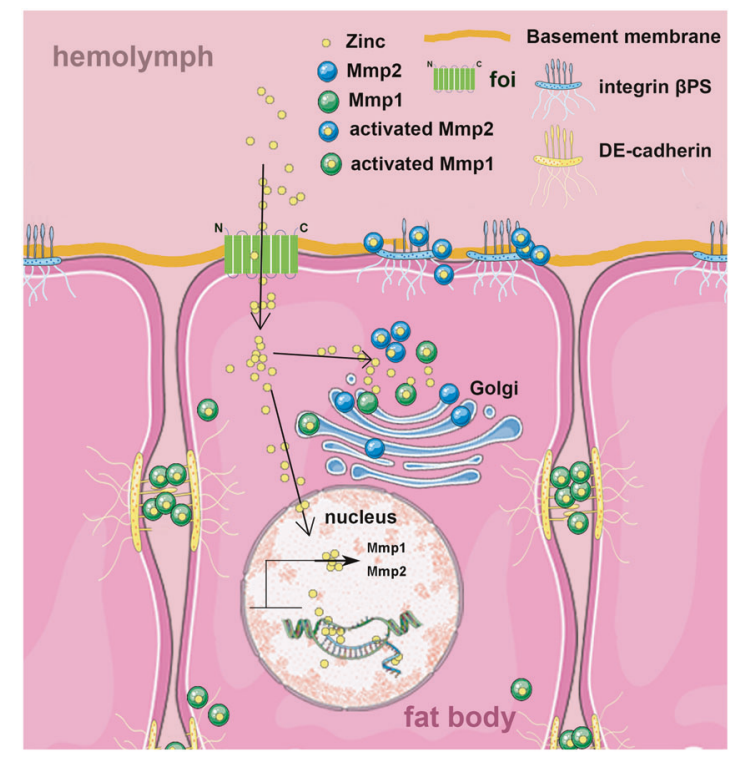

Fig. 7 A model to explain the effect of foi on cell dissociation. In the fat body of Drosophila melanogaster, foi transports zinc into cytosol. In addition to direct activating $\mathrm{Mmp}$ activity, the increased zinc level in the cytosol also results in increased zinc in the nucleus which could induce the transcription of Mmp1 and Mmp2. Mmps are involved in the progression of cell dissociation by promoting the degradation and hydrolysis of extracellular matrix components. 
level of Mmp1 and Mmp2 could be modulated by the cellular zinc levels mediated by zinc transporter foi. Our findings expand our knowledge of Mmp activity in development and show that cytosolic zinc level promotes cell dissociation of fat body cells by governing $\mathrm{Mmp}$ activity. According to our findings, zinc may regulate the activity of Mmps through two aspects: on the one hand, zinc directly binds an extended zinc-binding motif of Mmps to modulate their activities; on the other hand, zinc modulates Mmps' transcription to regulate their protein levels. But how the regulation of zinc modulates the transcription of Mmps awaits further investigation.

Interestingly, foi is homolog to mammalian ZIP6 and ZIP10 $[20,62]$. It has been reported that the zinc transporters ZIP6 and ZIP10 are highly expressed in several breast cancers and associate with cancer invasion and metastasis [63-65]. ZIP6 reduces the expression of E-cadherin in mammalian breast cancer cells and forms a heteromer with ZIP10, contributing to cell migration process $[63,66,67]$. EMT is a process to investigate cancer cell migration, invasion and metastatic dissemination [68]. During the EMT, non-motile epithelial cells are dispersed into individual motile and invasive cells by dissolving the cell-cell and cell-BM junctions which is involved in Mmps [66, 68, 69]. Besides, foi is involved in regulating cell migration in some tissues of Drosophila $[26,70]$. So we propose that foi may participate in the development and progression of cancer. With the help of the Drosophila malignant tumour model, $\mathrm{Raf}^{\mathrm{GOF}} \mathrm{Scrib}^{-/-}$and $\operatorname{Ras}^{\mathrm{V} 12} \mathrm{gl}^{-1-}$, we found that the tumour overgrowth, invasion and distant metastasis could be inhibited by foi knockdown in tumour clones. So we provided in vivo genetic evidence that manipulating zinc transporters can greatly modulate cancer progress. Moreover, we figure out the underlying mechanism is that the intracellular zinc regulates the expression of $\mathrm{Mmps}$ in vivo and then modulates their activities.

\section{DATA AVAILABILITY}

The data that support the findings of this study are available from the corresponding author upon reasonable request.

\section{REFERENCES}

1. Cui N, Hu M, Khalil RA. Biochemical and biological attributes of matrix metalloproteinases. Prog Mol Biol Transl Sci. 2017;147:1-73.

2. Ota I, Li XY, Hu Y, Weiss SJ. Induction of a MT1-MMP and MT2-MMP-dependent basement membrane transmigration program in cancer cells by Snail1. Proc Natl Acad Sci USA. 2009;106:20318-23.

3. Gonzalez-Avila G, Sommer B, Mendoza-Posada DA, Ramos C, Garcia-Hernandez AA, Falfan-Valencia R. Matrix metalloproteinases participation in the metastatic process and their diagnostic and therapeutic applications in cancer. Crit Rev Oncol Hematol. 2019;138:172-172.

4. Vandenbroucke RE, Libert $C$. Is there new hope for therapeutic matrix metalloproteinase inhibition? Nat Rev Drug Discov. 2014;13:904-27.

5. Chang D, Wang YC, Bai YY, Lu CQ, Xu TT, Zhu L, et al. Role of P38 MAPK on MMP activity in photothrombotic stroke mice as measured using an ultrafast MMP activatable probe. Sci Rep. 2015;5:16951.

6. Calap-Quintana P, Gonzalez-Fernandez J, Sebastia-Ortega N, Llorens JV, Molto MD. Drosophila melanogaster models of metal-related human diseases and metal toxicity. Int J Mol Sci. 2017;18:1456.

7. Gutierrez E, Wiggins D, Fielding B, Gould AP. Specialized hepatocyte-like cells regulate Drosophila lipid metabolism. Nature. 2007;445:275-80.

8. Arrese EL, Soulages JL. Insect fat body: energy, metabolism, and regulation. Annu Rev Entomol. 2010;55:207-25.

9. Xiao GR, Liu ZH, Zhao MR, Wang HL, Zhou B. Transferrin 1 functions in iron trafficking and genetically interacts with ferritin in Drosophila melanogaster. Cell Rep. 2019;26:748-58.

10. Hoshizaki DK, Lunz R, Ghosh M, Johnson W. Identification of fat-cell enhancer activity in Drosophila melanogaster using P-element enhancer traps. Genome. 1995;38:497-506.

11. Srivastava A, Pastor-Pareja JC, Igaki T, Pagliarini R, Xu T. Basement membrane remodeling is essential for Drosophila disc eversion and tumor invasion. Proc Natl Acad Sci USA. 2007;104:2721-6.
12. Wasser M, Osman ZB, Chia W. EAST and Chromator control the destruction and remodeling of muscles during Drosophila metamorphosis. Dev Biol. 2007;307:380-93.

13. Page-McCaw A, Serano J, Sante JM, Rubin GM. Drosophila matrix metalloproteinases are required for tissue remodeling, but not embryonic development. Dev Cell. 2003;4:95-106.

14. Page-McCaw A. Remodeling the model organism: matrix metalloproteinase functions in invertebrates. Semin Cell Dev Biol. 2008;19:14-23.

15. Bond ND, Nelliot A, Bernardo MK, Ayerh MA, Gorski KA, Hoshizaki DK, et al. ssFTZ F1 and matrix metalloproteinase 2 are required for fat-body remodeling in Drosophila. Dev Biol. 2011;360:286-96.

16. Jia $\mathrm{Q}$, Liu Y, Liu H, Li S. Mmp1 and Mmp2 cooperatively induce Drosophila fat body cell dissociation with distinct roles. Sci Rep. 2014;4:7535.

17. Maret W. Zinc biochemistry: from a single zinc enzyme to a key element of life. Adv Nutr. 2013;4:82-91.

18. Bafaro E, Liu YT, Xu Y, Dempski RE. The emerging role of zinc transporters in cellular homeostasis and cancer. Sig Transduct Target Ther. 2017;2:17029.

19. Richards $C D$, Burke R. A fly's eye view of zinc homeostasis: novel insights into the genetic control of zinc metabolism from Drosophila. Arch Biochem Biophys. 2016;611:142-9.

20. Xiao GR, Zhou B. What can flies tell us about zinc homeostasis? Arch Biochem Biophys. 2016;611:134-41.

21. Holanda AOD, de Oliveira ARS, Cruz KJC, Severo JS, Morais JBS, da Silva BB, et al. Zinc and metalloproteinases 2 and 9: what is their relation with breast cancer? Rev Assoc Med Bras. 2017;63:78-84.

22. Lye JC, Richards CD, Dechen K, Warr CG, Burke R. In vivo zinc toxicity phenotypes provide a sensitized background that suggests zinc transport activities for most of the Drosophila Zip and ZnT genes. J Biol Inorg Chem. 2013;18:323-32.

23. Dechen KS, Richards CD, Lye JC, Hwang JEC, Burke R. Compartmentalized zinc deficiency and toxicities caused by ZnT and Zip gene over expression result in specific phenotypes in Drosophila. Int J Biochem Cell B. 2015;60:23-33.

24. Van Doren M, Mathews WR, Samuels M, Moore LA, Broihier HT, Lehmann R. fear of intimacy encodes a novel transmembrane protein required for gonad morphogenesis in Drosophila. Development. 2003;130:2355-64.

25. Mathews WR, Wang FD, Eide DJ, Van Doren M. Drosophila fear of intimacy encodes a Zrt/IRT-like protein (ZIP) family zinc transporter functionally related to mammalian ZIP proteins. J Biol Chem. 2005;280:787-95.

26. Pielage J, Kippert A, Zhu MY, Klambt C. The Drosophila transmembrane protein fear-of-intimacy controls glial cell migration. Dev Biol. 2004;275:245-57.

27. Carrasco-Rando M, Atienza-Manuel A, Martin P, Burke R, Ruiz-Gomez M. Fear-ofintimacy-mediated zinc transport controls the function of zinc-finger transcription factors involved in myogenesis. Development. 2016;143:1948-57.

28. Wang XX, Wu YT, Zhou B. Dietary zinc absorption is mediated by ZnT1 in Drosophila melanogaster. FASEB J. 2009;23:2650-61.

29. Pastor-Pareja JC, Xu T. Shaping cells and organs in Drosophila by opposing roles of fat body-secreted collagen IV and perlecan. Dev Cell. 2011;21:245-56.

30. Toth M, Fridman R.Assessment of gelatinases (MMP-2 and MMP-9) by gelatin zymography.Methods Mol Med. 2001;57:163-74.

31. Wei T, Ji X, Xue J, Gao Y, Zhu X, Xiao G. Cyanidin-3-O-glucoside represses tumor growth and invasion in vivo by suppressing autophagy via inhibition of the JNK signaling pathways. Food Funct. 2021;12:387-96.

32. Argue KJ, Neckameyer WS. Altering the sex determination pathway in Drosophila fat body modifies sex-specific stress responses. Am J Physiol Regul Integr Comp Physiol. 2014;307:82-92.

33. Schmid MR, Anderl I, Vesala L, Vanha-aho LM, Deng XJ, Ramet M, et al. Control of Drosophila blood cell activation via Toll signaling in the fat body. PLoS ONE. 2014;9:e102568.

34. Burdette SC, Walkup GK, Spingler B, Tsien RY, Lippard SJ. Fluorescent sensors for $\mathrm{Zn}^{2+}$ based on a fluorescein platform: synthesis, properties and intracellular distribution. J Am Chem Soc. 2001;123:7831-41.

35. Sinclair SA, Sherson SM, Jarvis R, Camakaris J, Cobbett CS. The use of the zincfluorophore, Zinpyr-1, in the study of zinc homeostasis in Arabidopsis roots. New Phytol. 2007;174:39-45.

36. Andres AJ, Cherbas P. Tissue-specific ecdysone responses: regulation of the Drosophila genes Eip28/29 and Eip40 during larval development. Development. 1992;116:865-76.

37. Andres AJ, Fletcher JC, Karim FD, Thummel CS. Molecular analysis of the initiation of insect metamorphosis: a comparative study of Drosophila ecdysteroidregulated transcription. Dev Biol. 1993;160:388-404.

38. Antoniewski C, O'Grady MS, Edmondson RG, Lassieur SM, Benes H. Characterization of an EcR/USP heterodimer target site that mediates ecdysone responsiveness of the Drosophila Lsp-2 gene. Mol Gen Genet. 1995;249:545-56.

39. Le Du MH, Stigbrand T, Taussig MJ, Menez A, Stura EA. Crystal structure of alkaline phosphatase from human placenta at $1.8 \mathrm{~A}$ resolution. Implication for a substrate specificity. J Biol Chem. 2001;276:9158-65. 
40. Qiao W, Ellis C, Steffen J, Wu CY, Eide DJ. Zinc status and vacuolar zinc transporters control alkaline phosphatase accumulation and activity in Saccharomyces cerevisiae. Mol Microbiol. 2009;72:320-34.

41. Qin $Q$, Wang $X$, Zhou B. Functional studies of Drosophila zinc transporters reveal the mechanism for dietary zinc absorption and regulation. BMC Biol. 2013;11:101.

42. Nelliot A, Bond N, Hoshizaki DK. Fat-body remodeling in Drosophila melanogaster. Genesis. 2006;44:396-400.

43. Stevens LJ, Page-McCaw A. A secreted MMP is required for reepithelialization during wound healing. Mol Biol Cell. 2012;23:1068-79.

44. Loffek S, Schilling O, Franzke CW. Biological role of matrix metalloproteinases: a critical balance. Eur Respir J. 2011;38:191-208.

45. Wu M, Pastor-Pareja JC, Xu T. Interaction between Ras(V12) and scribbled clones induces tumour growth and invasion. Nature. 2010;463:545-65.

46. Doggett K, Grusche FA, Richardson HE, Brumby AM. Loss of the Drosophila cell polarity regulator scribbled promotes epithelial tissue overgrowth and cooperation with oncogenic Ras-Raf through impaired Hippo pathway signaling. BMC. Dev Biol. 2011;11:57.

47. Parisi F, Vidal M. Epithelial delamination and migration lessons from Drosophila. Cell Adh Migr. 2011;5:366-72.

48. Bell GP, Thompson BL. Colorectal cancer progression: lessons from Drosophila? Semin Cell Dev Biol. 2014;28:70-77.

49. Woessner JF Jr. Matrix metalloproteinases and their inhibitors in connective tissue remodeling. FASEB J. 1991;5:2145-54.

50. Jia Q, Chen X, Wu L, Ruan Z, Li K, Li S. Matrix metalloproteinases promote fat body cell dissociation and ovary development in Bombyx mori. J Insect Physiol. 2018;111:8-15.

51. Kambe T, Tsuji T, Hashimoto A, Itsumura N. The physiological, biochemical, and molecular roles of zinc transporters in zinc homeostasis and metabolism. Physiol Rev. 2015;95:749-84.

52. McCall KA, Huang C, Fierke CA. Function and mechanism of zinc metalloenzymes. J Nutr. 2000;130:1437-46.

53. Klein T, Geurink PP, Overkleeft HS, Kauffman HK, Bischoff R. Functional proteomics on zinc-dependent metalloproteinases using inhibitor probes. ChemMedChem. 2009;4:164-70.

54. Tallant C, Marrero A, Gomis-Ruth FX. Matrix metalloproteinases: fold and function of their catalytic domains. Biochim Biophys Acta. 2010;1803:20-28.

55. Duivenvoorden WC, Hirte HW, Singh G. Use of tetracycline as an inhibitor of matrix metalloproteinase activity secreted by human bone-metastasizing cancer cells. Invas Metast. 1997;17:312-22.

56. Rupp PA, Visconti RP, Czirok A, Cheresh DA, Little CD. Matrix metalloproteinase 2-integrin alpha(v)beta3 binding is required for mesenchymal cell invasive activity but not epithelial locomotion: a computational time-lapse study. Mol Biol Cell. 2008;19:5529-40.

57. Kanada KN, Nakatsuji T, Gallo RL. Doxycycline indirectly inhibits proteolytic activation of tryptic kallikrein-related peptidases and activation of cathelicidin. J Invest Dermatol. 2012;132:1435-42.

58. Yoo MH, Kim TY, Yoon YH, Koh JY. Autism phenotypes in ZnT3 null mice: involvement of zinc dyshomeostasis, MMP-9 activation and BDNF upregulation. Sci Rep. 2016;6:28548.

59. Hara T, Takeda TA, Takagishi T, Fukue K, Kambe T, Fukada T. Physiological roles of zinc transporters: molecular and genetic importance in zinc homeostasis. J Physiol Sci. 2017;67:283-301.

60. Vallee BL, Falchuk KH. The biochemical basis of zinc physiology. Physiol Rev. 1993;73:79-118.

61. Amich J, Calera JA. Zinc acquisition: a key aspect in Aspergillus fumigatus virulence. Mycopathologia. 2014;178:379-85.

62. Murakami M, Hirano T. Intracellular zinc homeostasis and zinc signaling. Cancer Sci. 2008;99:1515-22.

63. Kagara N, Tanaka N, Noguchi S, Hirano T. Zinc and its transporter ZIP10 are involved in invasive behavior of breast cancer cells. Cancer Sci. 2007;98:692-7.

64. Taylor KM, Morgan HE, Smart K, Zahari NM, Pumford S, Ellis IO, et al. The emerging role of the LIV-1 subfamily of zinc transporters in breast cancer. Mol Med. 2007;13:396-406

65. Hogstrand C, Kille P, Ackland ML, Hiscox S, Taylor KM. A mechanism for epithelialmesenchymal transition and anoikis resistance in breast cancer triggered by zinc channel ZIP6 and STAT3 (signal transducer and activator of transcription 3). Biochem J. 2013;455:229-37.

66. Grunert $S$, Jechlinger $M$, Beug $H$. Diverse cellular and molecular mechanisms contribute to epithelial plasticity and metastasis. Nat Rev Mol Cell Biol. 2003;4:657-65.

67. Brethour D, Mehrabian M, Williams D, Wang XZ, Ghodrati F, Ehsani S, et al. A ZIP6ZIP10 heteromer controls NCAM1 phosphorylation and integration into focal adhesion complexes during epithelial-to-mesenchymal transition. Sci Rep. 2017;7:40313.
68. Yilmaz M, Christofori G. EMT, the cytoskeleton, and cancer cell invasion. Cancer Metast Rev. 2009;28:15-33.

69. Lee MH, Vasioukhin V. Cell polarity and cancer-cell and tissue polarity as a noncanonical tumor suppressor. J Cell Sci. 2008;121:1141-50.

70. Moore LA, Broihier HT, Van Doren M, Lunsford LB, Lehmann R. Identification of genes controlling germ cell migration and embryonic gonad formation in Drosophila. Development. 1998;125:667-78.

\section{ACKNOWLEDGEMENTS}

The authors appreciate the gifts of Mmp2 antibody from Dr. Sheng Li (South China Normal University, Guangzhou, Guangdong Province, China), fly stocks from Dr. Bing Zhou (Tsinghua University, Beijing, China), Dr. Jose C. PASTOR-PAREJA (Tsinghua University, Beijing, China) and Dr. Mark Van Doren (Johns Hopkins University, Baltimore, MD, USA). The authors are also grateful to the Bloomington Drosophila Stock Center (Indiana University, Bloomington, IN, USA) and the Vienna Drosophila RNAi Center (Vienna, Austria) for fly stocks.

\section{AUTHOR CONTRIBUTIONS}

W.T. contributed to Methodology, Investigation, Data curation, Formal analysis, Conceptualization and Writing-original draft. J.X. contributed to Investigation, Data curation, Formal analysis, Conceptualization and Writing-review. Y.Q. contributed to Methodology, Investigation, Data curation and Writing-review. L.G., W.L. and G.Y. contributed to Methodology and Data curation. X.G. contributed Conceptualization, Writing-review \& editing, Project administration, Supervision and Funding acquisition. All authors read and approved the final paper.

\section{FUNDING}

This project was funded by the National Natural Science Foundation of China (31671284), the Fundamental Research Funds for the Central Universities (JZ2020HGPA0115) and Youth Science and Technology Talents Support Program (2020) by Anhui Association for Science and Technology (RCTJ202001).

\section{COMPETING INTERESTS}

The authors declare no competing interests.

\section{ETHICAL APPROVAL}

This study was approved by the Ethics Committee of Hefei University of Technology.

\section{ADDITIONAL INFORMATION}

Supplementary information The online version contains supplementary material available at https://doi.org/10.1038/s41419-021-04147-z.

Correspondence and requests for materials should be addressed to Guiran Xiao.

Reprints and permission information is available at http://www.nature.com/ reprints

Publisher's note Springer Nature remains neutral with regard to jurisdictional claims in published maps and institutional affiliations.

Open Access This article is licensed under a Creative Commons Attribution 4.0 International License, which permits use, sharing, adaptation, distribution and reproduction in any medium or format, as long as you give appropriate credit to the original author(s) and the source, provide a link to the Creative Commons license, and indicate if changes were made. The images or other third party material in this article are included in the article's Creative Commons license, unless indicated otherwise in a credit line to the material. If material is not included in the article's Creative Commons license and your intended use is not permitted by statutory regulation or exceeds the permitted use, you will need to obtain permission directly from the copyright holder. To view a copy of this license, visit http://creativecommons. org/licenses/by/4.0/.

(c) The Author(s) 2021 